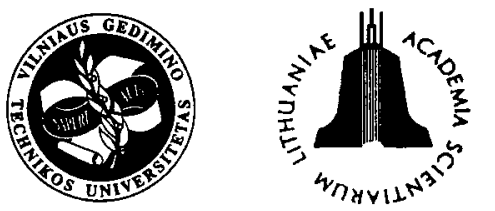

\title{
EVALUATION OF VARIABILITY IN SUBGRADE LOADS
}

\author{
Ryszard Porębski ${ }^{1}$, Igoris Podagèlis ${ }^{2}$ \\ ${ }^{1}$ Institute of Civil Engineering, Faculty of Civil and Environmental Engineering, Piotrowo-5, \\ 61-638Poznan, Poland. E-mail: rporebski@sol.put.poznan.pl \\ 2 Dept of Roads, Vilnius Gediminas Technical University, Sauletekio al. 11, LT-2040 \\ Vilnius, Lithuania. E-mail: igpod@ap.vtu.lt
}

Received 09 Oct 2001; accepted 21 Nov 2002

\begin{abstract}
The paper presents an analysis of variability in vertical stresses in the sleeper base. The research deals with the stresses caused by the track load by an ET 22 locomotive depending on the manner of pressure transfer by sleepers. Four schemes of force distribution under sleepers are being analysed. The research was carried out in Poznan Civil Engineering Institute.
\end{abstract}

Keywords: permanent way, axle load, load distribution, calculating stress, subgrade deformation.

\section{Introduction}

The forces loading the subgrade have a dynamic character and are characterised by a big variability and heterogeneity along the length and width of the track [1-4]. The main reasons causing differentiation of loads transferred onto the subgrade are variable dynamic forces loading the structure and roughness and heterogeneity of the structure and sleeper base [3-5]. The aim of the research findings of which are discussed in this paper was to determine and describe the variability in stresses in the upper sector of the subgrade, which are caused by different schemes of load transfer by the sleepers to the ballast. Particular attention was paid to the phenomenon of decay of variability (heterogeneity) in stresses at the subgrade depth. The research also makes it possible to determine the maximum stress amounts in the subgrade, the knowledge of which is indispensable when designing subgrade supports [5]. Issue of subgrade stability is also analysed in Vilnius Gediminas Technical University Road Department [6].

\section{Description of carried out research}

A continuous horizontal beam supported by elastic supports was assumed for a railway structure calculation model, which allows to determine the rail pressure on individual sleepers. The solution of the continuous beam system was carried out by the force method. As the external load of the structure, locomotive ET 22 was assumed, with two three-axle wheel sets of the axle base of $1,75 \mathrm{~m}$ and pressure of $196 \mathrm{kN}$ per axle. The calcula- tions were done for rails $\mathrm{S} 60\left(\mathrm{~J}_{\mathrm{x}}=3055 \mathrm{~cm}^{4}\right)$ and sleepers spaced at the length of $1=0,60 \mathrm{~m}$. The analysis omits the stresses deriving from the structure weight and ground deadweight.

The values of normal vertical stresses in an arbitrary point of the subgrade were determined by means of Boussinesq formula, with the application of stress superposition method [7,8]. The calculations allow for the interaction of nine neighbouring sleepers, whose bases were divided into 40 parts (the sleeper was cross-divided into 2 parts and length-divided into 20 parts). Each of the elements was assigned an elementary force, which was generated as a result of a specific distribution of forces affecting the individual sleeper. Four schemes of force distribution were proposed, which are supposed to reflect the feasible manners of pressure transfer through wooden and concrete sleepers to the ballast. The schemes were shown in Fig 1.

Vertical stresses in the subgrade were calculated for these schemes of force distribution under the bottom surface of the sleeper and they were broken down into diagrams. Further part of the paper analyses these stresses.

\section{Analysis of stress distribution in subgrade}

Calculated for all the four load schemes, distributions of vertical stresses in the subgrade along the track under the rail axis were broken down into Figs 2, 3 and 4. The calculations were done at the depths $\mathrm{z}=0,25 \mathrm{~m}$, $\mathrm{z}=0,50 \mathrm{~m}$ and $\mathrm{z}=0,75 \mathrm{~m}$, measured from the sleeper bottom. 


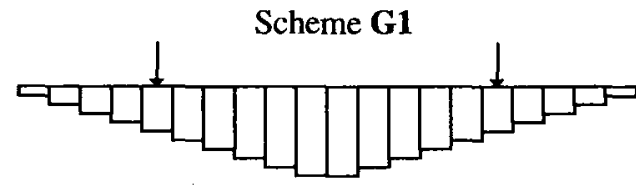

Scheme G3

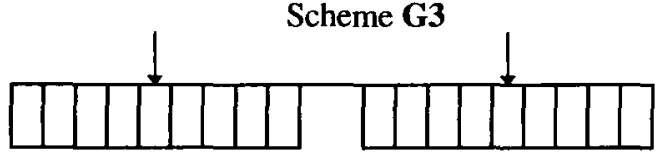

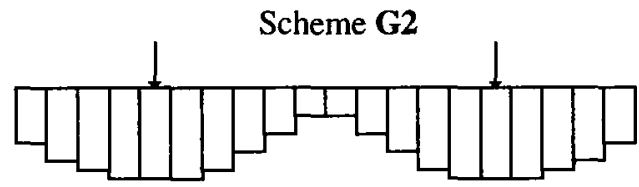

Scheme G4

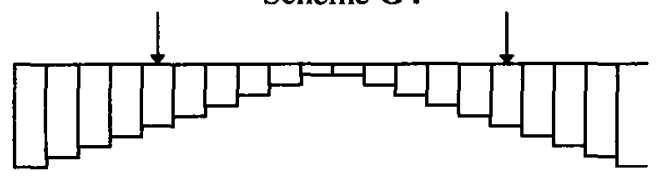

Fig 1. Schemes of distribution of stresses transferred through sleepers to ballast

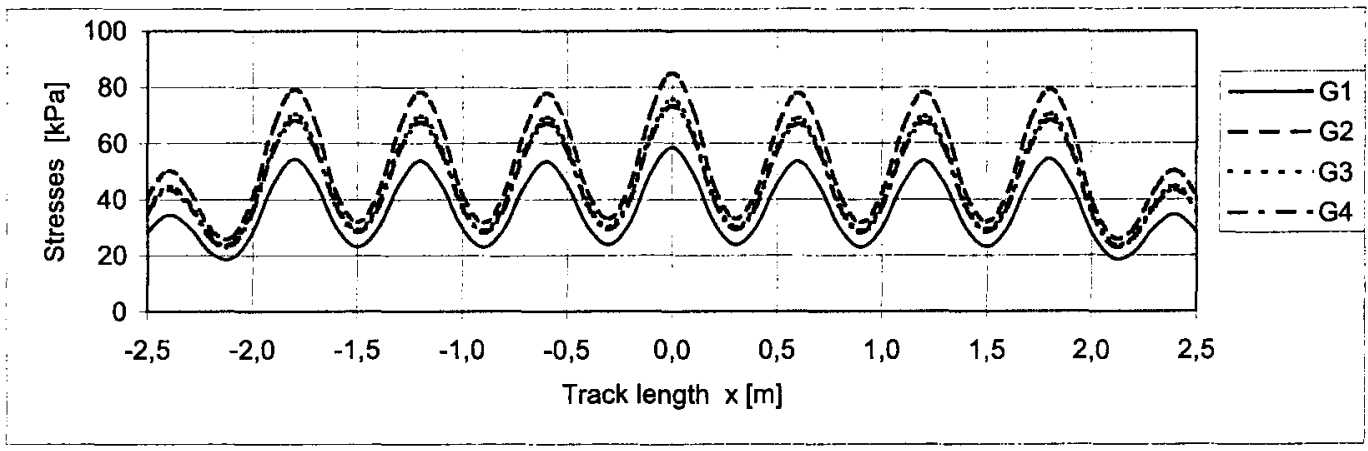

Fig 2. Diagram of stress variability along track, under rail axis, at depth of $0,25 \mathrm{~m}$, depending on force distribution under sleeper surface

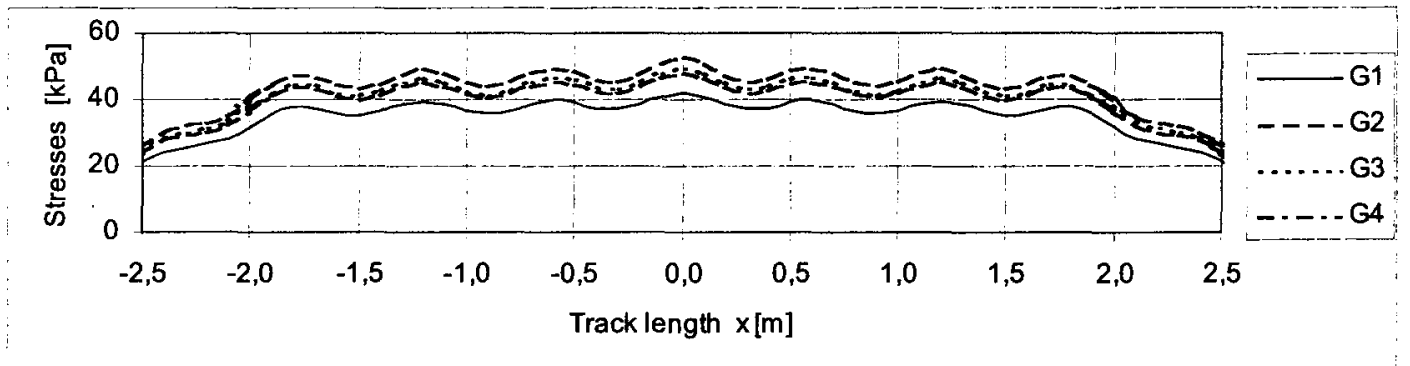

Fig 3. Diagram of stress variability along track, under rail axis, at depth of $0,50 \mathrm{~m}$, depending on type of force distribution under sleeper surface

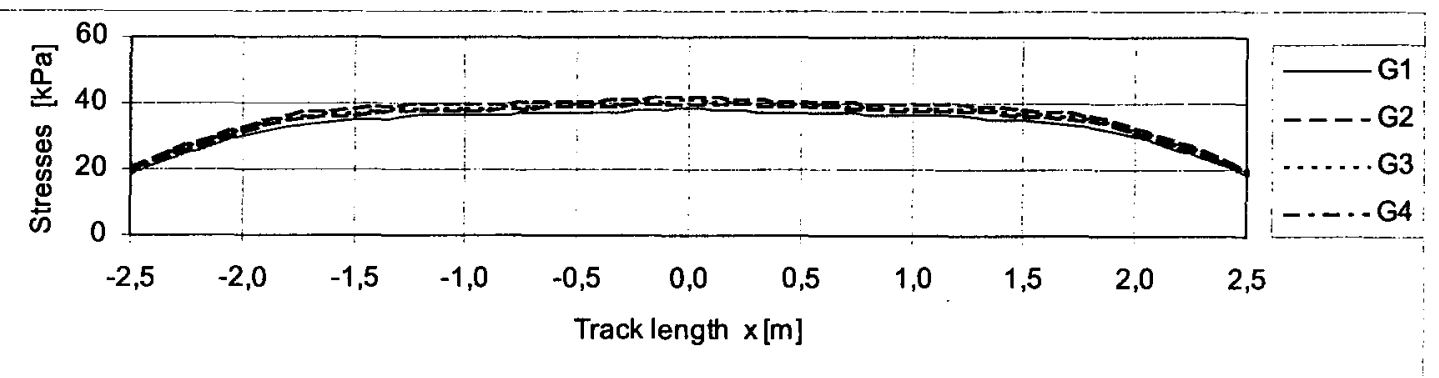

Fig 4. Diagram of stress variability along track, under rail axis, at depth of $0,75 \mathrm{~m}$, depending on type of force distribution under sleeper surface 
The characteristic feature of these distributions is the fact that at small depths there is a big differentiation in the stresses along the track, and the value of these stresses is strongly influenced by the manner of load transfer by the sleepers. For the under-rail section the highest stress values occur for load scheme G2. The maximum value of these stresses is $85,1 \mathrm{kPa}$ and occurs at the depth of $0,25 \mathrm{~m}$. As the depth increase, the stress value is reduced to $38,3 \mathrm{kPa}$ at the depth of $0,70 \mathrm{~m}$. For load scheme $\mathbf{G l}$ the stress values are the lowest. At the depth of $0,25 \mathrm{~m}$ the difference in the stress values in the schemes is about $45 \%$.

As the depth increases, the stress value is reduced and the amplitude of stresses is levelled along the track. The measure of stress equalisation along the track is the reduction in the difference between the maximum stresses, calculated under the sleeper centre, and the minimum ones, occurring at half length between the neighbouring sleepers. This index, expressed as percentage, is about $60 \%$ at the depth of $0,25 \mathrm{~m}$. It decreases as the depth increases. At the depth of $0,50 \mathrm{~m}$ it is about $13 \%$, and at the depth of $0,70 \mathrm{~m}$ it is only $2,5 \%$. The quantity of this parameter does not depend on the load scheme.

Further presented are the results illustrating the phenomenon of stress decay, which occurs as the subgrade depth increases. Fig 5 presents the break-down of stress distribution at the subgrade depth, induced by the influence of loads of different pressure distribution schemes under the most heavily loaded sleeper at the height of the rail axis.
The diagram analysis (Fig 5) shows that the biggest stresses are induced by the load distributed according to scheme G2, whereas the smallest stresses are the effect of load distributed according to scheme G1. The difference between them is considerable, because at the depth of $0,10 \mathrm{~m}$ it is about $33 \%$. As the depth increases, there can be observed the phenomenon of decay of differences in the distribution of stresses coming from the different schemes. From the depth of about $0,75 \mathrm{~m}$ on the manner of load transfer through the sleepers to the ballast has no influence on the value of stresses in the subgrade.

Fig 6 presents the stress distribution in the longitudinal section of the subgrade, under the rail axis, and Fig 7 presents the stress distribution in the cross-section of the track, under the most heavily loaded sleeper. These stresses derive from the distribution of loads under the sleeper surface according to scheme G2. The figures present a break-down of the stresses occurring at four depths: $z=0,25 \mathrm{~m}, \mathrm{z}=0,35 \mathrm{~m}, \mathrm{z}=0,50 \mathrm{~m}$ and $\mathrm{z}=0,75 \mathrm{~m}$.

The analysis of Fig 6, presenting stress distribution in an under-rail longitudinal section, shows that as the depth increases, the maximum stress values (under the sleeper) are reduced. In this section at the depth $\mathrm{z}=0,25 \mathrm{~m}$ the maximum stress value is $85,6 \mathrm{kPa}$, and at the depth $z=0,75 \mathrm{~m}$ it is reduced more than twice and equals $42,4 \mathrm{kPa}$. The minimum stress values, occurring between sleepers (in spaces), are not subject to considerable variation at each of the depths. As the depth

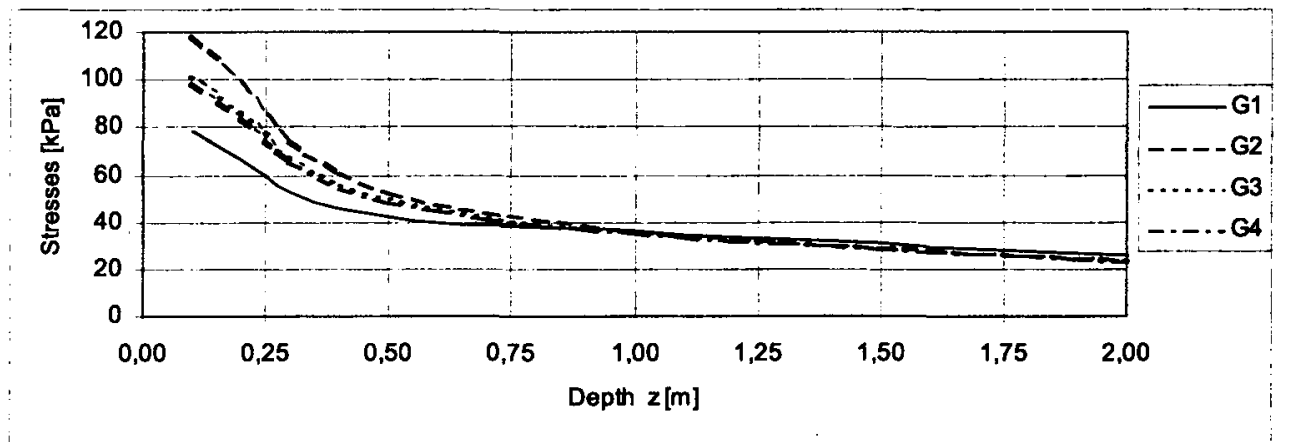

Fig 5. Distribution of stresses at subgrade depth under the most heavily loaded sleeper

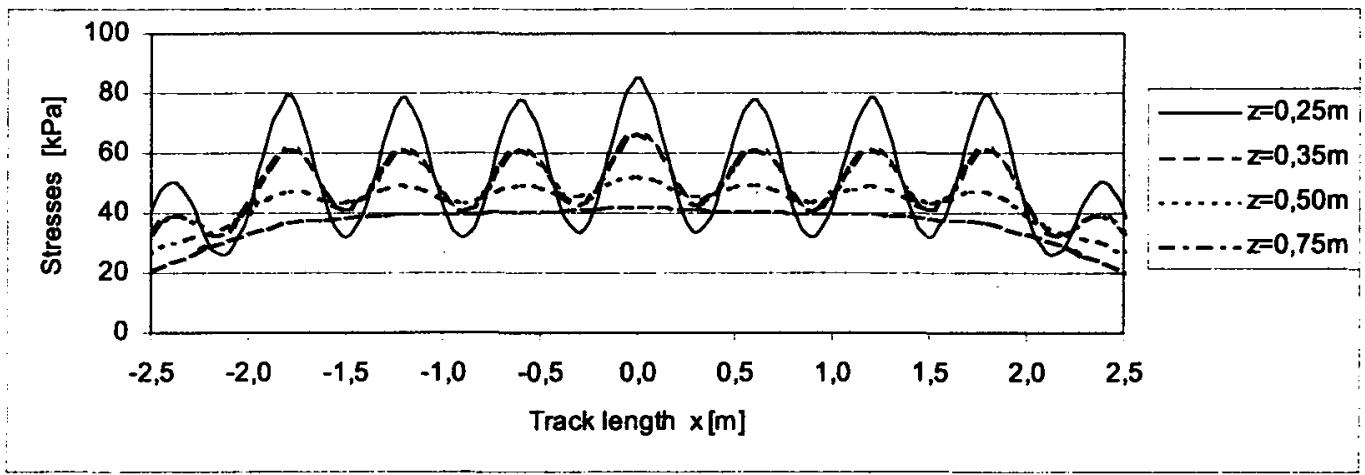

Fig 6. Diagram of stress variability in subgrade under rail axis at different depths for scheme G2 


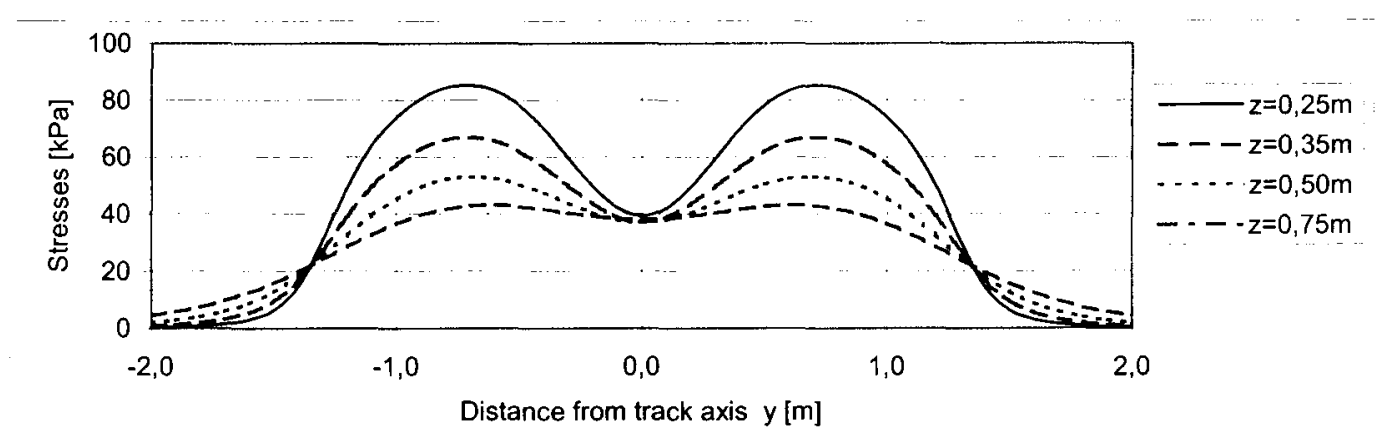

Fig 7. Diagram of stress variability in subgrade at different depths in cross-section of track for scheme G2

increases the stresses are levelled (homogenous) along the track. This phenomenon is proved by the differences between the maximum (under the sleeper) and minimum (in the space) stress values, which decrease as the depth increases.

In the case of the cross-section (Fig 7) steady decrease in the maximum stress values (under the rail) was observed as the depth increased, whereas the minimum stress values inside the sleeper did not change considerably and remained in the order of $38 \mathrm{kPa}$. It can also be assumed that at the depth of about $0,75 \mathrm{~m}$ the stress distribution along the sleeper is close to uniform. The results of subgrade supports research prove our conclusions.

\section{Conclusions}

On the basis of the carried out calculations and analyses it can be stated that at a small depth (directly under the ballast) there is a big variability in the stresses along and across the track; this variability is strongly influenced by the manner of pressure transfer through sleepers. Comparing the effects of different schemes of load distribution under the bottom surface of the sleeper it was found that as deep as $0,75 \mathrm{~m}$, ie at the subsoil level (below the protective layer), these distributions have little effect on maximum stress values in the subgrade. Also at the depth of about $0,75 \mathrm{~m}$ the distributions of vertical stresses in the subgrade are close to uniform.

\section{References}

1. Porębski R. Analysis of uneven distribution of load to track subgrade. In: Material from the $\mathrm{X}$ scientific conference "Railway Track". Spaua, 1999, p. 32-36.

2. Porębski R. Analysis of load distribution in subgrade in exploitable line. ZNPP, Building, No 35, WUPP, Poznań, 1992, p. 16-18.

3. Porębski R. Calculations of stress distribution in subgrade, occurring due to uneven loads in road upper construction. ZNPP, Building, No 36, WUPP, Poznań, 1993, p. 22-24.

4. Siewczyński $\ell$. Interaction of road upper construction and subgrade. Polytechnics of Poznań, Digest, No 66, WUPP, Poznań, 1974, p. 28-30.

5. Porębski $R$. Influence of uneven load distribution in subgrade to road upper construction. ZNPP, Building, No 40, WUPP, Poznań, 1995, p. 15-20.

6. Sakalauskas K., Podagèlis I., Cerniauskaitè L., Povilaitienè I. Research project „Technologies of resource savings for infrastructure maintenance“, Vilnius, 2001. $69 \mathrm{p}$

7. Wiłun Z. Geotechnics, WKit, Warszawa, 1976. 204 p.

8. Informational base of railway track. Research Project led by Henryk Bałuch, WKiL, Warszawa, 1990. $121 \mathrm{p}$. 